Original Research Article

\title{
Evaluation of anxiolytic properties of BacoMind extract of plant Bacopa monnieri Linn. in comparison with diazepam in rodent model
}

\author{
Rajni Rathore $^{1}$, Tarun Arora ${ }^{2}$, Rashmi Karabasappa Mamadi ${ }^{3}$
}

${ }^{1}$ Department of Pharmacology, Atal Bihari Vajpayee Institute of Medical Sciences, Dr Ram Manohar Lohia Hospital and Post Graduate Institute of Medical Education and Research, New Delhi, India ${ }^{2}$ Department of Pharmacology, Lady Hardinge Medical College, New Delhi, India

${ }^{3}$ Department of Pharmacology, St. John's Medical College and Hospital, Bangalore, Karnataka, India

Received: 06 September 2019 Accepted: 05 October 2019

*Correspondence to:

Dr. Tarun Arora,

Email: doctortarunarora@ gmail.com

Copyright: (C) the author(s), publisher and licensee Medip Academy. This is an openaccess article distributed under the terms of the Creative Commons Attribution NonCommercial License, which permits unrestricted noncommercial use, distribution, and reproduction in any medium, provided the original work is properly cited.

\begin{abstract}
Background: Anxiety is a state characterized by somatic, emotional, cognitive, and behavioral components, associated with significant disability. The pharmacotherapy for anxiety remains limited for achievable safety and tolerability of the medicines. Benzodiazepines use associated with side effects like psychomotor impairment and addiction liability. Due to the ADRs associated with antianxiety drugs, the drug trials have focused on screening herbal medicines that are reportedly used in the treatment of anxiety and which have minimal side effects.

Methods: The anxiolytic activity was examined by using the elevated plus maze (EPM) and open field test (OFT), forty Albino wistar strain rats of both sex of weighing 120 to $200 \mathrm{~g}$ were divided into four groups of ten rats each.. Group 1 received vehicle (normal saline); group 2 received diazepam (1 $\mathrm{mg} / \mathrm{kg}$ ); groups 3 and 4 received BacoMind ${ }^{\mathrm{TM}}, 30$ and $60 \mathrm{mg} / \mathrm{kg}$ oral, respectively.

Results: Rats treated with diazepam $(1 \mathrm{mg} / \mathrm{kg}$, p.o.) showed significant $(\mathrm{p}<0.001)$ increase in the percentage of open arms entries and time spent whereas, in closed arm the number of entries and time spent were significantly $(\mathrm{p}<0.05)$ decreased. Intraperitonial administration of BacoMind ${ }^{\mathrm{TM}}$ extract of plant Bacopa monnieri Linn. exhibited significant $(\mathrm{p}<0.05)$ increase in the number of open arm entries and time spent with significant $(\mathrm{p}<0.05)$ reduction in number of entries and time spent in the closed arm as compared to group 1. BacoMind $^{\mathrm{TM}}$ treated rats also produced significant increase in the number of rearings $(p<0.05)$, assisted rearings and number of squares crossed $(p<0.01)$.

Conclusions: BacoMind ${ }^{\mathrm{TM}}$ extract of plant Bacopa monnieri Linn possess significant anxiolytic activity in the rats. It can be a promising anxiolytic agent.
\end{abstract}

Keywords: Anxiolytic, Diazepam, Elevated plus maze, Open field test, BacoMind $^{\mathrm{TM}}$

\section{INTRODUCTION}

Anxiety is a psychological and physiological state characterized by somatic, emotional, cognitive, and behavioral components, associated with significant disability (including educational and occupational) which has a negative impact on the quality of life. ${ }^{1}$ Anxiety neurosis was reported to be prevalent in 16.5 per thousand individuals, with a marginally higher prevalence in urban settings than in rural settings $(106: 100) .^{2}$ Anxiety has become a significant area of psychopharmacological research during this decade, as its current prevalence estimates across 44 countries ranged between $0.9 \%$ and $28.3 \%$, with the global prevalence calculated to be $7.3 \% .^{3}$ 
Benzodiazepines are the major class of compounds commonly prescribed for treating anxiety. However, their use is associated with side effects like psychomotor impairment, potentiating of other central depressant drugs and addiction liability. ${ }^{4}$ For these reasons, newer antianxiety drugs with better efficacy and decreased side effect profile is needed.

Herbal medicines have revealed benefit in the treatment of anxiety disorders. Bacopa monniera is one such ayurvedic medicine. It is also referred to as Bacopa monnieri, Herpestis monniera, water hyssop, and "Brahmi," It has been used by Ayurvedic medical practitioners in India for almost 3000 years and is classified as a "medhyarasayana", a drug used to improve memory and intellect (medhya) and memory enhancing. ${ }^{5,6}$ In addition to the antiamnesic effects, antiulcerogenic activities. ${ }^{7,8}$

It is also used as cardiac tonic, digestive aid, and to improve respiratory function in cases of bronchoconstriction. ${ }^{8}$ Recently it was reported that B. monniera also exerts anti-inflammatory and antiarthritis activity, antioxidant and antistress, properties of Bacopa has showed protection against free radical damage in cardiovascular disease and certain types of cancer. ${ }^{10,11}$ Support for efficacy of anxiolytic property was also shown by B. monnieri.

BacoMind $^{\mathrm{TM}}$ is a standardized phytochemical composition derived from the plant Bacopa monnieri Linn. B. monnieri Linn is also known as B. monniera L, H. monniera Linn, Monniera cunefolia Michx, Graticola monnieri L. or Lysimachia monnieri L. Cent. It is commonly called as Brahmi or thyme leaved gratiola. $B$. monnieri belongs to the family of plants called Scrophulariaceae. It is a perennial creeping annual plant found throughout the Indian subcontinent in wet, damp and marsh areas. ${ }^{12}$ Compounds responsible for the pharmacological effects of Bacopa include alkaloids, saponins, and sterols. The major chemical constituents shown to be responsible for the memory-facilitating action of B. monnieri are the steroidal saponins bacoside $\mathrm{A}$ and $\mathrm{B}$, as these compounds have shown to exert facilitatory effects on mental retention in avoidance response in rats. ${ }^{13}$

BacoMind $^{\mathrm{TM}}$ is a chemically standardized formulation having 9 different bioactive compounds by HPLC and HPTLC. It is also biologically tested using assays like Lipoxygenase inhibition, Butyrylcholinesterase inhibition, ABTS radical scavenging, ORAC and DPPH assays. An HPLC method together with an optimised extraction procedure was developed. ${ }^{10}$ For the estimation of $1-4$ in $B$. monnieri to enable standardisation of the latter. Concentration ranges of the analytes in samples of $B$. monnieri collected from different regions of India were $0.14-0.85 \%$ (w/w) (1), $0.12-0.69 \%$ (2), $0.05-0.72 \%$ (3) and $0.05-0.44 \%$ (4). The importance of using bacoside A, with known concentrations of $1-4$, as a reference standard for the routine analysis of $B$. monnieri is highlighted.

Preliminary animal studies has shown that B. Monnieri has learning enhancing ability, cognition facilitating property, augmentation of mental retention capacity, memory enhancing property, attenuation of dementia. ${ }^{6-10}$

The plant, plant extracts and isolated bacosides have been investigated for anxiolytic activity. ${ }^{14}$ Previous studies by Bhattacharya et al have demonstrated the anxiolytic property with standardized extract of Bacopa monniera in comparison with lorazepam. ${ }^{15}$ Thus this study is being carried out with the objective to assess the anxiolytic properties of a standardized formulation of Bacopa Monneria - BacoMind ${ }^{\mathrm{TM}}$ in rats using elevated plus maze apparatus in comparison with Diazepam.

\section{METHODS}

\section{Animals}

Albino Wistar strain rats of both sex of weighing 120 to $200 \mathrm{~g}$ were used were used, for this study. The animals were obtained from Central Animal house, St. John's National Academy of Health Sciences. They were housed in standard polypropylene cages. Three animals will be housed per cage with paddy husk. Animals were quarantined for 7 days before use and were excluded if the weight of rats were below $120 \mathrm{gms}$ and if they had any visible diseases. The animals were maintained under standard laboratory conditions $(12: 12 \mathrm{hr}$ light: dark cycles and temperature $24 \pm 2^{\circ} \mathrm{C}$ with free access to food and water ad libitum. All the experiments were carried out around the same time each day.

\section{Drugs and chemicals}

\section{Diazepam}

Diazepam tablets (Calmpose $5 \mathrm{mg}$, Ranbaxy Laboratories Limited Navi-Mumbai, India B-No. 1700593) were used as a standard drug. Diazepam was suspended in $0.5 \%$ of carboxymethyl cellulose in distilled water.

BacoMind $^{\mathrm{TM}}$ A standardized phytochemical composition derived from the plant B. monnieri Linn.

\section{Chemial standardization of BacoMind ${ }^{T M}$}

BacoMind is chemically standardized with 9 different bioactive compounds by HPLC and HPTLC. It is also biologically tested using assays like lipoxygenase inhibition, butyrylcholinesterase inhibition, ABTS radical scavenging, ORAC and DPPH assays. Bacomind is manufactured in GMP, NSF-GMP, ISO 9001-2008 and ISO 22000:2005 certified manufacturing facility.

Bacoside A, the putative bioactive component of the Indian medicinal plant $B$. monnieri, was found to be a 
mixture of saponins with bacoside A3 (1), bacopaside II (2), jujubogenin isomer of bacopasaponin $\mathrm{C}$ (3) and bacopasaponin C (4) as major constituents. An HPLC method together with an optimised extraction procedure was developed for the estimation of 1-4 in B. monnieri to enable standardisation of the latter. Concentration ranges of the analytes in samples of B. monnieri collected from different regions of India were $0.14-0.85 \%$ (w/w) (1), $0.12-0.69 \%$ (2), $0.05-0.72 \%$ (3) and $0.05-0.44 \%$ (4). The importance of using bacoside $A$, with known concentrations of 1-4, as a reference standard for the routine analysis of $B$. monnieri is highlighted.

BacoMind $^{\mathrm{TM}}$, an enriched phytochemical composition of B. monnieri extract will be obtained from Natural Remedies Pvt. Ltd, Bangalore. BacoMind ${ }^{\mathrm{TM}}$ (patent pending) is a standardized composition of the following bioactive constituents viz, bacoside A3 $(>5.0 \% \mathrm{w} / \mathrm{w})$, bacopaside I $(>7.0 \% \mathrm{w} / \mathrm{w})$, bacopaside II $(>5.5 \% \mathrm{w} / \mathrm{w})$, jujubogenin isomer of bacopasaponin $\mathrm{C}(>7.0 \% \mathrm{w} / \mathrm{w})$, bacopasaponin C $(>4.5 \% \mathrm{w} / \mathrm{w})$, bacosine $(>1.5 \% \mathrm{w} / \mathrm{w})$, luteolin $(>0.2 \% \mathrm{w} / \mathrm{w})$, apigenin $(>0.1 \% \mathrm{w} / \mathrm{w})$ and $\beta$ sitosterol-D-glucoside $(>0.3 \% \mathrm{w} / \mathrm{w})$. This composition is further standardized using the following in vitro bioassays viz, lipoxygenase inhibition assay (IC50<600 $\mu \mathrm{g} / \mathrm{ml}$ ), ABTS radical scavenging assay (IC50<100 $\mu \mathrm{g} / \mathrm{ml}$ ), DPPH assay (IC50<200 $\mu \mathrm{g} / \mathrm{ml}$ ) and butyrylcholinesterase inhibition assay (IC50<3000 $\mu \mathrm{g} / \mathrm{ml})$.

\section{Procedure}

\section{Housing and handling}

The study will be conducted using adult male wistar albino rats of 120 to $200 \mathrm{gm}$ and will be housed in colony cages with a $12 \mathrm{~h}$ light dark cycle. The animals will have free access to standard pellet chow and drinking water ad libitum. Experiments were conducted between 9 am to 12 pm every time. Study was conducted as per the CPSCEA guidelines.

\section{Drug administration}

- $\quad$ Bacomind 30 mg.kg P.O administration

- Bacomind $60 \mathrm{mg} / \mathrm{kg}$ P.O administration

- Diazepam $1 \mathrm{mg} / \mathrm{kg}$ P.O administration

Anxiolytic effect testing using the model.

The study used 40 animals. The animals were assigned to one of the 4 groups.

\section{Grouping}

To study the anti-anxiety activity of BacoMind, elevated plus maze model was used.

Groups are divided as follows (Figure 1).

- Group I vehicle (normal saline) at a dose of $1.5 \mathrm{ml} / \mathrm{kg}$ body weight.

- Group II received BacoMind at a dose of $30 \mathrm{mg} / \mathrm{kg}$ body weight

- Group III received BacoMind at a dose of $60 \mathrm{mg} / \mathrm{kg}$ body weight.

- Group IV received standard drug, diazepam $1 \mathrm{mg} / \mathrm{kg}$ body weight.

Separate groups of animals were used for different models and all the groups received the drugs intraperitonially, given $30 \mathrm{~min}$ prior to the start of the experiment. Concentration of drugs was so adjusted that all the animals in the group received the same volume of preparation throughout the study.

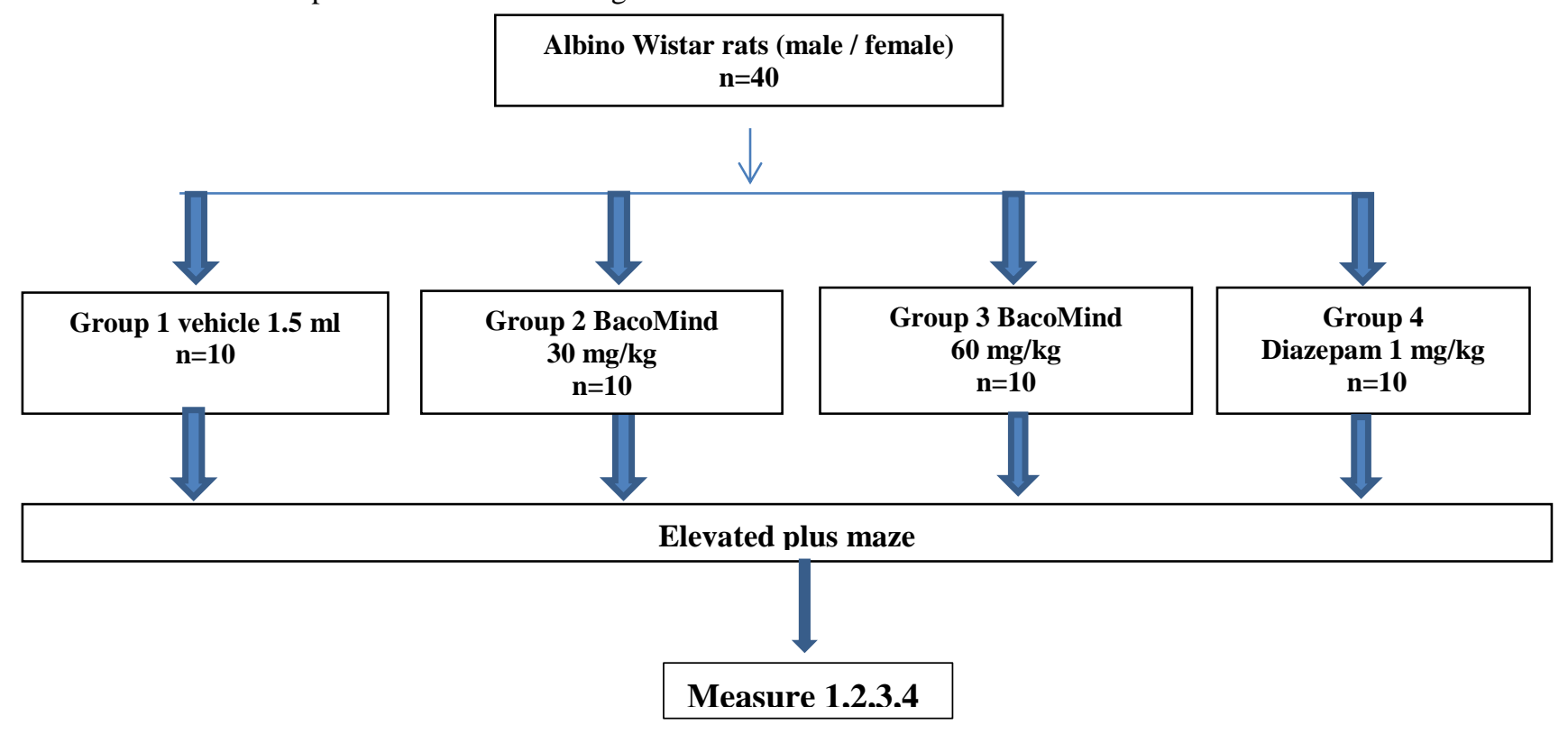

Figure 1: The animal experiment process flowchart.

1) Number of open arm and closed arm entries; 2) Head dipping; 3) Rearing; 4) Grooming and stretch attends. 


\section{Elevated plus maze apparatus}

After $1 \mathrm{~h}$ of oral administration of vehicle, diazepam and BacoMind ${ }^{\mathrm{TM}}$, Phytochemical composition of B. monnieri extract were assessed for anxiolytic behavior using elevated plus-maze test. The elevated plus-maze apparatus consists of two opposite open arms $(20 \mathrm{~cm} \times 7$ $\mathrm{cm})$, crossed with two closed arms of same dimensions with $30 \mathrm{~cm}$ high wall. The arms are connected with central square $(7 \mathrm{~cm} \times 7 \mathrm{~cm})$. The walls and floor, of the apparatus colored with black paint and the apparatus was kept in sound proof and 200 lux light illuminated room. To assess plus maze test, the rats were individually placed on the central platform facing towards open arm. The percentage of time spent (duration) in open arms and frequency of open arm entries were counted for a period of 5 min. All precaution was taken to ensure that no external stimuli, other than the height of plus maze could invoke anxiety in the animals. Arm entry was defined as all four paws having crossed the dividing line Elevated plus maze (EPM) model for anxiety between an arm and the central area. ${ }^{16}$ The procedure was conducted in a sound attenuated room. After each test, EPM was cleaned with spirit. During $5 \mathrm{~min}$ test period the following measures are taken,

- The number of entries into the open arm.

- The number of entries into the closed arm.

- Time spent in the open arm.

- Time spent in the closed arm.

- The percentage of time spent in the open arms and number of open arm entries were calculated using the formulas $[100 \times$ open/ $($ open + enclosed $)]$ and $(100 \times$ open / total entries), respectively. ${ }^{17}$

Recorded for a period of 5 minutes using a stop watch.

All the four will be measured separately and compared among the groups (Figure 1).

\section{Open field}

This test was used to detect angiogenic and anxiolytic activity under identical situations. Various types of Open field apparatus have been used to test the rats. ${ }^{18}$ The apparatus consisted of a wooden box $(60 \times 60 \times 60 \mathrm{~cm})$.
The arena of the open field was divided into 16 squares $(15 \times 15 \mathrm{~cm})$, the four inner squares in the center and 12 squares in the periphery along the walls. The experimental room was dark and sound attenuated. The open field arena was illuminated with a $40-\mathrm{W}$ lamp, focusing on the field from a height of about 75-100 cm. After 60 min of oral treatment with vehicle, diazepam and BacoMind ${ }^{\mathrm{TM}}$ extract of plant B. monnieri Linn, animals were placed individually in one of the corner squares and number of rearings, assisted rearings and number of squares crossed were observed for the period of 5 min. ${ }^{19}$

\section{Sample size}

The study will be conducted using 40 animals in 4 groups. Each group consists of 10 animals. The animals will be assigned to one of the four groups - test substance (BacoMind), control substance (Diazepam), and vehicle.

\section{Statistical analysis}

The data was collected in case record forms and then entered into excel spreadsheet 2007.

Statistical analysis was performed using Microsoft Excel - 2007. Data was described as Mean \pm Standard deviation. One way ANOVA (ANalysis Of VAriance) followed by post hoc Tukey's test. Multiple comparison test was used for analysis of data between the four groups. Categorical variables will be analyzed using chi-square test. For all inferential statistical tests a two tailed $\mathrm{p}<0.05$ was considered significant.

\section{RESULTS}

\section{Anxiolytic activity}

The vehicle-treated rats $(1.5 \mathrm{ml} / \mathrm{kg}$, oral normal saline) spent more time in closed arm and showed less entries in open arm compared to closed arm of the maze at $5 \mathrm{~min}$. Animal treated with diazepam (1 mg/kg, p. o.) showed significant $(\mathrm{p}<0.001)$ increase in the percentage of open arms entries as well as time spent in open arm whereas, in closed arm number of entries and time spent were significantly $(\mathrm{p}<0.001)$ decreased.

Table 1: Comparison of BacoMind ${ }^{\mathrm{TM}}$ and diazepam on behavior of rats in elevated plus maze test $(\mathbf{n}=10)$.

\begin{tabular}{|lllllll|}
\hline $\begin{array}{l}\text { Group and dose } \\
\text { (mg/kg, i.p) }\end{array}$ & Mean no. of entries in & $\begin{array}{l}\text { Mean time spent in } \\
\text { (sec) }\end{array}$ & $\begin{array}{l}\text { Percentage } \\
\text { of open arm } \\
\text { entries }\end{array}$ & $\begin{array}{l}\text { Percentage of } \\
\text { time spent in } \\
\text { open arm }\end{array}$ \\
\cline { 2 - 7 } & Open arm & Close $\mathbf{~ a r m ~}$ & Open arm & Close arm & & \\
\hline Vehicle (Normal saline) & $5.2 \pm 1.00$ & $22.7 \pm 1.5$ & $22.2 \pm 3.1$ & $259.7 \pm 10.6$ & $17.8 \pm 2.4$ & $7.9 \pm 1.2$ \\
\hline Bacomind 30mg/kg & $11.2 \pm 1.3 \mathrm{~b}$ & $11.8 \pm 1.0 \mathrm{c}$ & $46.2 \pm 3.0 \mathrm{c}$ & $136.7 \pm 7.6 \mathrm{~b}$ & $48.1 \pm 1.8 \mathrm{c}$ & $25.5 \pm 1.9 \mathrm{c}$ \\
\hline Bacomind 60mg/kg & $11.5 \pm 1.1 \mathrm{~b}$ & $13.7 \pm 1.6 \mathrm{~b}$ & $51.2 \pm 3.2 \mathrm{c}$ & $145.5 \pm 11.9 \mathrm{a}$ & $46.3 \pm 3.0 \mathrm{c}$ & $27.0 \pm 2.6 \mathrm{c}$ \\
\hline Diazepam 1mg /kg & $11.5 \pm 1.1 \mathrm{~b}$ & $13.2 \pm 0.8 \mathrm{~b}$ & $37.7 \pm 2.7 \mathrm{a}$ & $140.2 \pm 15.6 \mathrm{a}$ & $50.4 \pm 5.4 \mathrm{c}$ & $21.7 \pm 1.8 \mathrm{c}$ \\
\hline
\end{tabular}

Values represent mean \pm SEM $(n=10), a=p<0.05 ; b=p<0.01 ; c=p<0.001$ vs. vehicle-treated control group (one-way ANOVA followed by post hoc Tukey's test). \% OAE=percentage of open arm entries. $\bullet \% \mathrm{TSOA}(\mathrm{s})=$ percentage of total time spent in open arm in seconds. 
Table 2: Comparison of comparison of BacoMind ${ }^{\mathrm{TM}}$ and Diazepam on behavior of rats in open field test $(\mathrm{n}=10)$.

\begin{tabular}{|llll|}
\hline Treatment $(\mathbf{m g} / \mathrm{kg}$, p. o.) & No. of rearing & No. of assisted rearing & No. of square crossed \\
\hline Vehicle & $10.7 \pm 1.8$ & $21.0 \pm 3.9$ & $126.8 \pm 5.4$ \\
\hline Diazepam $(\mathbf{1})$ & $16.5 \pm 1.2 \mathrm{a}$ & $33.0 \pm 2.9 \mathrm{a}$ & $177.8 \pm 8.9 \mathrm{~b}$ \\
\hline Bacomind 30 $\mathbf{~ m g} / \mathbf{k g}$ & $16.5 \pm 1.2 \mathrm{a}$ & $33.5 \pm 3.3 \mathrm{a}$ & $186.8 \pm 9.9 \mathrm{c}$ \\
\hline Bacomind $60 \mathrm{mg} / \mathrm{kg}$ & $17.2 \pm 1.2 \mathrm{~b}$ & $36.5 \pm 2.9 \mathrm{~b}$ & $199.7 \pm 11.5 \mathrm{c}$ \\
\hline
\end{tabular}

Values represent mean \pm SEM $(n=10), a=p<0.05 ; b=p<0.01 ; c=p<0.001$ vs. vehicle-treated control group (one-way ANOVA followed by post hoc Tukey's test).

Administration of BacoMind ${ }^{\mathrm{TM}}(30$ and $60 \mathrm{mg} / \mathrm{kg}$, p.o, respectively) exhibited significant $(\mathrm{p}<0.01)$ increase in the percentage of number of open arm entries and time spent in open arm whereas, in the closed arm number of entries and time spent was significantly $(\mathrm{p}<0.01)$ reduced as compared to vehicle-treated group (Table 1 ).

\section{Open field test}

In the open field test (OFT), diazepam-treated mice showed significant increase $(\mathrm{p}<0.05)$ in the number of rearings, number of squares crossed and assisted rearings during 5-min interval of test as compared to vehicletreated groups. BacoMind ${ }^{\mathrm{TM}}$ extract of plant $B$. monnieri Linn (30 and $40 \mathrm{mg} / \mathrm{kg}$ ) also produced significant increase in the number of rearings $(\mathrm{p}<0.05)$, assisted rearings and squares crossed $(\mathrm{p}<0.01)$ (Table 2$)$.

\section{DISCUSSION}

Anxiety is a negative emotion that occurs in response to perceived threats that can come from internal or external sources and can be real or imagined. ${ }^{20}$ The incidence of anxiety in the community is very high and associated with lot of morbidity. ${ }^{21}$ Ethnomedical and pharmacological knowledge about the plant under study would allow us to evaluate central nervous system activity, which could be used to treat anxiety disorders. The present work has proved the ethno medical claim of BacoMind ${ }^{\mathrm{TM}}$ extract of plant B. monnieri Linn effect in rats.

The EPMT is used to evaluate psychomotor performance and emotional aspects of rodents. Results obtained on the elevated plus maze after treatment with BacoMind ${ }^{\mathrm{TM}}$ extract of plant B. monnieri Linn (30 and $40 \mathrm{mg} / \mathrm{kg}$ ) revealed anxiolytic activity, since increases in open arm entry parameters are the most representative indices of anxiolytic activity. ${ }^{22}$ Time spent on the central platform appears to be related to decision making and/or risk assessment, and the total arm entries is a measure reflecting changes in anxiety or in general activity. ${ }^{23}$

The OFT is used to evaluate the animal emotional state. The open field model examines anxiety-related behavior characterized by the normal aversion of the animal to an open, brightly lit area. Thus, animals removed from their acclimatized cage and placed in environment express anxiety and fear, by showing alteration in all or some parameters. Anxiolytic treatments reduce such fearful behavior of animals in open field. ${ }^{24}$ Statistical analysis of the data obtained from these experiments supported anxiolytic like activity of BacoMind ${ }^{\mathrm{TM}}$ extract of plant $B$. monnieri Linn at both the doses (30 and $40 \mathrm{mg} / \mathrm{kg}$ ) as its effect shows significant increase in the number of rearings, number of assisted rearings and number of squares crossed, as compared to the vehicle-treated group, which indicates its anxiolytic-like effect.

Earlier reports on the chemical constituents of plants and their pharmacology suggest that plants containing bacoside $\mathrm{A}$, was assigned as 3-(a- L-arabinopyranosyl)-OB-D-glucopyranoside-10, 20-dihydroxy-16-keto-dammar24-ene. Bacoside A usually co-occurs with bacoside B, the latter differing only in optical rotation and may represent an artefact during the process of isolation of bacoside A. ${ }^{25}$ The present investigation was conducted with a standardized extract (bacoside A content $25.5 \pm 0.8 \%$ ) since such extracts have been shown to exhibit nootropic effect in rats. $^{26}$ BacoMind $^{\mathrm{TM}}$ has bacoside $\mathrm{A}$ as a major constituents and possess activity against many CNS disorders. ${ }^{5-7,11}$

The results obtained in this study suggest that the BacoMind $^{\mathrm{TM}}$ extract of plant $B$. monnieri Linn has anxiolytic properties. Thus, BacoMind ${ }^{\mathrm{TM}}$ has potential clinical applications in the management of anxiety disorders. Further investigations are warranted for elucidating the exact mechanism and bioactive compounds.

Funding: No funding sources

Conflict of interest: None declared

Ethical approval: The study was approved by the Institutional Ethics Committee

\section{REFERENCES}

1. Al-Gamal E. Quality of life, anxiety and depression among patients with chronic obstructive pulmonary disease and their spouses. Issues Ment Health Nurs. 2014;35(10):761-7.

2. Ganguli IH. Epidemiological findings on prevalence of mental disorders in India. Indian $\mathbf{J}$ Psychiatr. 2000;42:14-20.

3. Baxter AJ, Scott KM, Vos T, Whiteford HA. Global prevalence of anxiety disorders: a systematic review 
and meta-regression. Psychol Med. 2013;43(5):897910.

4. Masoumeh E, Mohammad K, Maryam FA. Coriandrum sativum: Evaluation of its anxiolytic effect in the elevated plus-maze. J Ethnopharmacol. 2005;96:365-70.

5. Russo A, Borrelli F. Bacopa monniera, a reputed nootropic plant: an overview. Phytomedicine. 2005;12(4):305-17.

6. Tripathi YB, Chaurasia S, Tripathi E, et al. Bacopa monniera Linn. as an antioxidant: mechanism of action. Indian J Exp Biol. 1996;34:523-6.

7. Prabhakar S, Saraf MK, Pandhi P, Anand A. Bacopa monniera exerts antiamnesic effect on diazepaminduced anterograde amnesia in mice. Psychopharmacology (Berl). 2008;200:27-37.

8. Goel RK, Sairam K, Babu MD, Tavares IA, Raman A. In vitro evaluation of Bacopa monniera on antiHelicobacter pylori activity and accumulation of prostaglandins. Phytomedicine. 2003;10:523-7.

9. Viji V, Shobha B, Kavitha SK, Ratheesh M, Kripa K, Helen A, et al. Betulinic acid isolated from Bacopa monniera (L.) Wettst suppresses lipopolysaccharide stimulated interleukin-6 production through modulation of nuclear factorkappaB in peripheral blood mononuclear cells. Int Immunopharmacol. 2010;10(8):843-9.

10. Viji V, Kavitha SK, Helen A. Bacopa monniera (L.) wettst inhibits type II collagen-induced arthritis in rats. Phytother Res. 2010;24(9):1377-83.

11. Chowdhuri DK, Parmar D, Kakkar P, et al. Antistress effects of bacosides of Bacopa monnieri: modulation of Hsp70 expression, superoxide dismutase and cytochrome P450 activity in rat brain. Phytother Res. 2002;16:639-45.

12. Kishore K, Singh M. Effect of bacosides, alcoholic extract of Bacopa monniera Linn. (brahmi), on experimental amnesia in mice. Indian $\mathrm{J}$ Exp Biol. 2005;43:640-5.

13. Deb DD, Kapoor P, Dighe RP, Padmaja R, Anand MS, D'Souza P, et al. In vitro safety evaluation and anticlastogenic effect of BacoMind on human lymphocytes. Biomed Environ Sci. 2008;21(1):7-23.

14. Gohil KJ, Patel JA. A review on Bacopa monniera: Current research and future prospects. Int $\mathrm{J}$ Green Pharm. 2010;4:1-9.
15. Bhattacharya SK, Ghosal S. Anxiolytic activity of a standardized extract of Bacopa monniera: an experimental study. Phytomedicine. 1998;5(2):77-82.

16. Alicia A Walf, Cheryl A Frye.The use of the elevated plus maze as an assay of anxiety-related behavior in rodents. Nat Protoc. 2007;2(2):322-8.

17. Nishino T, Takeuchi T, Takechi K, Kamei C. Anxiolytic Effects by Hypnotics. J Pharmacol Sci. 2008;107:349-54.

18. Rauniar GP, Deo S, Bhattacharya SK. Evaluation of anxiolytic activity of tensarin in mice. Kathmandu Univ Med J (KUMJ). 2007;5:188-94.

19. Yadav AV, Kawale LA, Nade VS. Anxiolytic effects of Mulberry leaves. Indian J Pharmacol. 2008;40:326.

20. Moser DK. The rust of life, Impact of anxiety on cardiac patients. Am J Crit Care. 2007;16:361-9.

21. Ghoshal S, Dutta SK. Erythrina chemical and pharmacological evaluation II Alkaloids of Erythina variegata. J Pharm Sci. 1972;61:1274-7.

22. Lister RG. Ethologically-based animal models of anxiety disorders. Pharmacol Ther 1990;46:321-40.

23. File SE. Factors controlling measures of anxiety and responses to novelty in the mouse. Behav Brain Res. 2001;125:151-7.

24. Mechan AO, Moran PM, Elliott M, Young AJ, Joseph MH, Green R. A comparison between dark agouti and Sprague-Dawely rats in their behaviour on the elevated plus-maze, open fi eld apparatus and activity meters and their response to diazepam. Psychopharmacology (Berl). 2002;159:188-95.

25. Singh HK, Dhawan BN. Effect of bacopa monniera linn. (btim1) extract on Avoidance responses in rat. J Ethnopharmacol. 1982;5:205-14.

26. Kasture SB, Kasture VS, Joshua AJ, Damodaran A, Amit A. Nootropic activity of BacoMind ${ }^{\mathrm{TM}}$, an enriched phytochemical composition from Bacopa monnieri. J Natural Remedies. 2007;7:166-73.

Cite this article as: Rathore R, Arora T, Mamadi RK. Evaluation of anxiolytic properties of BacoMind extract of plant Bacopa monnieri Linn. in comparison with diazepam in rodent model. Int $\mathrm{J}$ Basic Clin Pharmacol 2019;8:2506-11. 